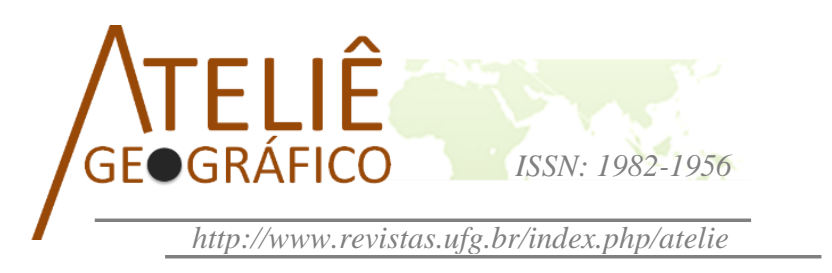

\title{
Territorialidades dos malucos de estrada em espaços públicos de João Pessoa/PB
}

\author{
Territorialities of Road crazies in public spaces in João \\ Pessoa/PB, Brazil
La territorialité des Fous de la Route dans des espaces publics à João Pessoa/PB, Brésil

\author{
Mirelli Albertha de Oliveira Gomes \\ Universidade Federal da Paraíba \\ mirelligomes@gmail.com
}

\author{
Doralice Sátyro Maia \\ Universidade Federal da Paraíba \\ doralicemaia@hotmail.com
}

\begin{abstract}
Resumo
Popularmente identificados como hippies, os artesãos nômades, que se autodenominam malucos de estrada, expressam uma cultura que se desenvolve inteiramente na rua, mudam constantemente de uma cidade para outra e estabelecemse como nômades. Em cada cidade que passam, ocupam os espaços públicos e criam a Pedra de Maluco, local onde desenvolvem o trabalho do artesanato juntamente com a construção do habitat. Este artigo objetiva caracterizar a Pedra de Maluco de João Pessoa/PB, localizada na Orla de Tambaú, como apropriação do espaço público pelos malucos de estrada. Através da abordagem etnográfica e da cartografia da ação, observou-se que a Pedra de Maluco configura-se como um território, ou mais especificamente, um nanoterritório (SOUZA, 2013). Ainda que nada tenha de edificado, está preenchida de códigos, rastros e limites invisíveis, o que implica na modificação dos significados e das expressões do espaço bem como na construção da identidade e dos valores dos malucos de estrada, transformando a Pedra de Maluco também em um Lugar.
\end{abstract}

Palavras-chaves: Malucos de estrada. Apropriação. Espaço público. Território.

\begin{abstract}
Popularly known as hippies, the nomadic craftsmen, who call themselves road crazies, express a culture that evolves entirely on the streets, are constantly changing from one city to another, and establish themselves as nomads. In every city they go, they settle in public spaces and create the Crazies Rock, a place where they make handicrafts and
\end{abstract}


build their habitat. The purpose of this article is to characterize the Crazies Rock in João Pessoa/PB, located on the beach of Tambaú, a public space appropriated by road crazies. The ethnographic approach and the occupation's cartography showed that the Crazies Rock is a territory, or more specifically, a nanoterritory (SOUZA, 2013). Although it has no buildings, the Crazies Rock has codes, trails, and invisible boundaries, which entails changes in meanings and expressions of the space, as well as the construction of the road crazies' identity and values, also transforming the Crazies Rock into one Place.

Keywords: Road crazies. Appropriation. Public urban space. Territory.

\begin{abstract}
Résumé
Populairement identifiés comme Hippies, les artisans nomades que s'appellent euxmêmes les Fous de la Route, expriment une culture développée entièrement dans la rue, ils changent des villes régulièrement et sont établis comme des nomades. Dans chaque ville qu'ils passent, ils occupent les espaces publics et créent la Pierre des Fous, endroit où ils développent leur travaux artisanaux en liaison avec la construction de leur habitat. L'objectif de cet article scientifique est de caractériser la Pierre des Fous de João Pessoa-PB, Brésil, située sur la promenade de la plage de Tambaú, comme l'appropriation d'espace public par les Fous de la Route. À travers une approche ethnographique et de la cartographie d'action, il était possible d'observer que la Pierre des Fous peut être classée comme un territoire ou plus spécifiquement, comme un nanoterritoire. (SOUZA, 2013). Malgré de n'avoir rien édifié, l'espace est rempli de codes, de traces et de limites invisibles que donnent l'origine à la modification des significations et des expressions, ainsi comme la construction d'identité et des valeurs des Fous de la Route, ce qui transforme la Pierre de Fous aussi dans un Lieu.

Mots-clés: Les Fous de la Route. Appropriation. Espace public. Territoire.
\end{abstract}

\title{
Introdução
}

Decorrente de um diálogo entre o movimento de contracultura norte-americano (CARRANZA, 2012) e sua tradução local dentro do contexto social, político e econômico brasileiro, os artistas e artesãos nômades são popularmente identificados como hippies, em virtude de uma semelhança ideológica e estética, muito embora rejeitem esse título e se reconheçam de fato como malucos de estrada.

Ainda que compartilhem das mesmas ideias de viverem à margem do sistema capitalista como os hippies, os malucos de estrada expressam uma cultura que se desenvolve inteiramente na rua, nos seus diversos aspectos, como o trabalho, a habitação e os lazeres, e, portanto, vivem nos centros urbanos, nos espaços públicos, como artistas e artesãos de rua.

Porém, diferenciam-se entre os moradores de rua, primeiramente, por escolherem esse modo de vida (MAIA, 2000), afastando qualquer perspectiva de análise de sujeitos carentes ou dependentes. Segundo, eles se identificam como itinerantes e mudam constantemente de uma cidade para outra, estabelecendo-se como nômades (BARBOSA, 2008), portanto não criam abrigos permanentes, tampouco possuem interesse em construir qualquer edificação para moradia.

Em cada cidade que passam, ocupam os espaços públicos e criam um local onde podem desenvolver o trabalho - produção e comercialização dos produtos artesanais - 
juntamente com a construção do habitat, colateralmente ou o mais perto possível um do outro.

Esse espaço de trabalhar e habitar denominam de Pedra de Maluco, que se caracteriza como um local de ocupação temporária dos malucos de estrada e de realização de todas as atividades cotidianas do grupo tal como produção, exposição e comercialização do trabalho artesanal, preparo de alimentos, montagem do espaço para descanso com papelões ou barracas de camping etc. (Figura 01a)

Em João Pessoa, a Pedra de Maluco está localizada na porção mais turística da cidade, a Praia de Tambaú. O Bairro de Tambaú como um todo é bastante misto em suas funções, possui residências unifamiliares, edifícios multifamiliares, mas, principalmente, uma grande quantidade de usos destinados ao comércio e ao turismo, como hotéis, restaurantes, agências de viagens, locadoras de veículos, lojas de artesanato, conveniências, quiosques e bares ao longo de toda a orla marítima, a Avenida Almirante Tamandaré. (Figura 01b)

Os malucos instalaram-se na calçada da Orla de Tambaú devido à grande movimentação de pessoas em todos os horários, principalmente de moradores e turistas que frequentam restaurantes, bares e lojas de artesanato, praticam esportes, caminham com amigos ou família ou usufruem da praia, propriamente dita. Assim, ali estando, no meio desse contínuo e quase ininterrupto fluxo de pessoas, os malucos oferecem suas peças de artesanato aos transeuntes. (Figura 01c)

Este artigo tem como objetivo caracterizar a Pedra de Maluco de João Pessoa, localizada na Orla de Tambaú, como uma apropriação do espaço público pelos malucos de estrada. Entende-se a apropriação como sendo um processo carregado de marcas do vivido e do valor de uso, no sentido estabelecido por Henri Lefebvre (2006).

De um espaço natural modificado para servir as necessidades e as possibilidades de um grupo, pode-se dizer que este grupo dele se apropria. (...) Tais espaços abundam, ainda que não seja sempre fácil dizer, em que e como, por quem e para quem, eles foram apropriados. (LEFEBVRE, 2006, p. 231-232, grifos do autor)

Assim como espaço público refere-se a um espaço, qualquer um, não importa a função de base, que corresponde à dimensão espacial da política, como locus da lei democrática, capaz de criar condições para unir uma dimensão física de copresença de indivíduos, diferenciados e racionais, a uma dimensão mais abstrata de comunicação social, onde a acessibilidade não pode estar condicionada a nenhum critério, senão àqueles previstos pela lei e legitimados por causa da igualdade de condições do respeito às liberdades individuais e ao bom convívio social. (GOMES, 2012) 


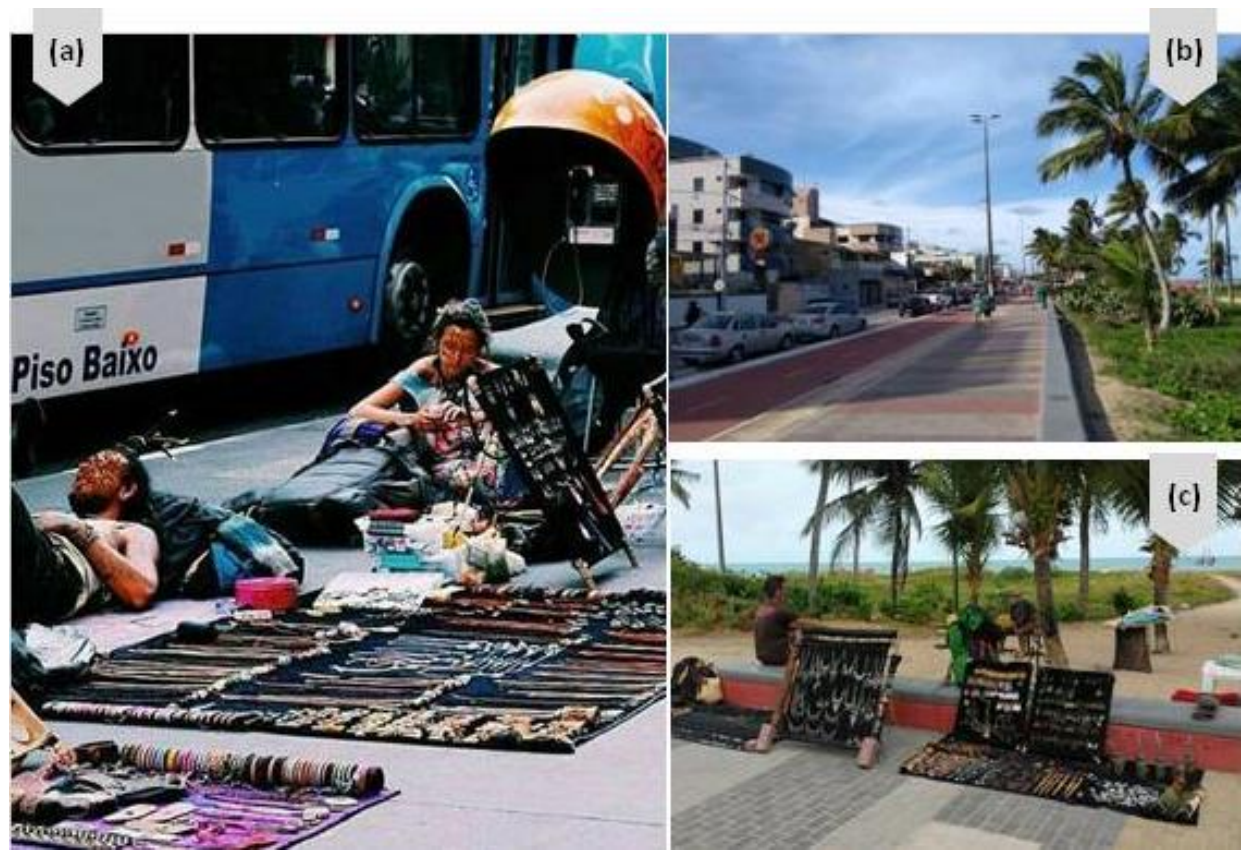

Figura 01 - (a) Pedra de Maluco em Cuiabá/MT. (b) Avenida Almirante Tamandaré, em João Pessoa/PB. (c) Pedra de Maluco na Orla de Tambaú, em João Pessoa/PB. Fonte: Fotografias de Mirelli Gomes (2018).

\section{Notas metodológicas: percursos transdisciplinares}

Para o estudo dos malucos de estrada, algumas concepções e procedimentos metodológicos do campo da Antropologia e da Geografia são necessários na investigação da cultura e do modo de vida, como a observação participante (MALINOWSKI, 1986; MAGNANI, 1984) e a cartografia da ação (RIBEIRO et al., 2001-2002).

A primeira etapa consistiu na abordagem etnográfica de Bronisław Malinowski (MALINOWSKI, 1986) e de José Guilherme Cantor Magnani (MAGNANI, 1984), que parte da observação direta através do convívio diário com os membros de uma determinada comunidade.

Na etnografia, convém o pesquisador participar do cotidiano da aldeia, enfrentar um dia mais ou menos semelhante ao do nativo, aprender a se comportar e sentir a diferença entre as maneiras locais corretas e incorretas, participar de jogos ou passeios, sentar-se, ouvir e participar das conversas. (MALINOWSKI, 1986)

Magnani atualiza as lições de Malinowski ao trazê-las para a Antropologia Urbana. Para o autor, deve-se "deixar de lado uma postura etnocêntrica e observá-los de perto e em seu próprio contexto" (1984, p.11, grifo nosso), assim como "é preciso estar 
atento a cada gesto, palavra ou hábito, por mais insignificantes ou exóticos que possam parecer". (ibid., p. 10)

Dessa forma, por meio de apontamentos diários e desenhos esquemáticos no caderno de bordo, fotografias e vídeos na câmera ou no celular, foram registradas as atividades mais recorrentes do cotidiano, as atitudes e a maneira de se comportar, o vocabulário próprio, as regras e o código de ética, a organização espacial, o levantamento dos objetos encontrados no local, os lugares frequentados e os caminhos mais percorridos pelos malucos de estrada no Bairro de Tambaú.

A segunda etapa metodológica consistiu na construção da cartografia da ação dos malucos de estrada, baseada no método homônimo de Ana Clara Torres Ribeiro (RIBEIRO et al., 2001-2002).

Para a autora, a cartografia da ação é a forma não oficial de representar a construção do espaço realizada pelo sujeito e pelos gestos dele e visa valorizar os espaços praticados, mostrar as dinâmicas dos espaços usados e dar maior visibilidade a contextos, lugares e narrativas de sujeitos sociais - como acontecem os trajetos, as lutas, as práticas, os movimentos, as apropriações e tudo que o sujeito faz do espaço. (RIBEIRO et al., 20012002).

Sendo assim, foram utilizados como base para a cartografia da ação os mapas por livre acesso do Google Maps (GOOGLE, 2018), como também foi consultada a base de dados da Prefeitura Municipal de João Pessoa, o Jampa em Mapas (PMJP, 2018), que foram redesenhados e acrescidos das informações coletadas na etapa etnográfica.

\section{A Pedra de Maluco: a formação de um território}

Para analisar a Pedra de Maluco enquanto espaço do maluco de estrada, é preciso compreender o habitat para além da materialidade do ambiente construído e investigá-lo sob uma dimensão subjetiva, buscando uma concepção que não dependa da ideia de casa ou de abrigo, mas considerando que a relação espacial do maluco de estrada refere-se tanto à apropriação enquanto morador de rua, quanto à construção de um habitat nômade, enquanto praticante do nomadismo. A princípio se fará uma caracterização da Pedra de Maluco, pensando este espaço enquanto território (SOUZA, 2013).

As Pedras de Maluco se estabelecem em locais de maior movimentação de pessoas a pé na cidade - em virtude de grandes equipamentos públicos e privados ou setores mais comerciais ou turísticos, com fluxo de pessoas que vão consumir. Portanto, praças, mercados, rodoviárias, estações, orlas marítimas e fluviais, parques, universidades, shoppings centers, calçadões, centros e ruas comerciais, largos, atrativos naturais cachoeiras, rios e praias, e, eventualmente, festas e shows musicais.

A formação da Pedra nasce com a exposição do trabalho e com a colocação dos panos de chão de todos os malucos que estão de passagem por aquela cidade, que se juntam para expor e habitar determinado espaço público mais favorável à suas atividades. (Figura 02a) 
Nesse processo, torna-se fundamental a percepção dos diferentes grupos que habitam ou trabalham na rua a fim de que se coloquem espacialmente distantes dos favozeiros, flanelinhas, prostitutas, ambulantes etc.

Se ao longo do dia não surge nenhuma contrariedade com os habitantes nem com as normas urbanísticas locais - fiscalizadas pela polícia ou pela secretaria de urbanismo da cidade, permanecem no local escolhido e dali vão em busca do que precisam.

Tal como o nômade primitivo que descobre a floresta ou o ambiental natural, o maluco de estrada inicia sua descoberta da cidade, como um nômade urbano em busca de alimento e proteção, procurando onde pode realizar todas as necessidades que vão surgindo durante o dia - comer, dormir, ir ao banheiro, deitar, sentar, produzir, beber, cozinhar, etc.

Pouco a pouco, o maluco vai conhecendo cada comércio daquela região ou bairro onde está instalada a Pedra, estabelecendo relações de confiança com outros comerciantes e elegendo aqueles pontos comerciais mais amigáveis, os mais baratos, os que os aceitam, como também convivendo com os habitantes da cidade, de forma que seja possível a continuidade da sua permanência.

Ao redor da área de exposição, começam a ocupar os bancos e a colocar caixas de papelóes, quando não o fazem com seus próprios cobertores, a fim de montar um espaço próprio de sentar, deitar ou trabalhar para ficarem durante o dia enquanto esperam os clientes.

Quando vão dormir, desarmam os panos, guardam na mochila e, quando não armam as barracas e papelões na própria Pedra, vão procurar lugares próximos dali, mas longe de outros moradores de rua, os favozeiros. Procuram algum mocó, que quer dizer, na linguagem do grupo, lugares cobertos, marquises, coretos, quiosques, bares fechados etc. Procuram dormir todos os malucos juntos, de modo a protegerem um ao outro durante a noite. (Figura $02 \mathrm{~b}$ )

Os malucos dormem sobre papelões e geralmente carregam na mochila pelo menos um cobertor e um casaco para usarem durante a noite. Alguns utilizam barraca, para garantir a privacidade do casal ou da família - quando tem filhos, para que as crianças fiquem mais protegidas e menos expostas ao frio e aos transeuntes.

Em cidades consideradas mais violentas ou quando, numa percepção subjetiva, se sente que não vai ser seguro dormir na rua naquela cidade, é preciso procurar um hotel ou uma pousada de baixo custo para passar a noite. Raramente, mas também acontece, algum morador da cidade convida-os para a sua casa, oferece abrigo, comida e banho, mesmo sem os conhecerem.

A partir do estabelecimento da Pedra de Maluco, os malucos de estrada criam um território (SOUZA, 2013) no espaço público, tanto por serem moradores de rua, de acordo com Vieira et al. (1992), ou mesmo como nômades, segundo Deleuze e Guattari (2012). 
Vieira et al. declaram que, "o mapeamento dos recursos utilizados pela população de rua e dos pontos de pernoite evidencia uma circunscrição geográfica, ou seja, sugere a existência de um espaço sócio-geográfico delimitado" (1992, p. 109, grifo nosso), assim como Deleuze e Guattari afirmam que "o nômade tem território" (2012, p.53, grifo nosso) e "o nômade se distribui num espaço liso, ele ocupa, habita, mantém esse espaço, e aí reside seu princípio territorial” (ibid., p.55, grifo nosso).

Para Vieira et al. (op.cit., p. 109),

A predominância do comércio (...) representa a possibilidade de alternativas, trazidas pela aluência e circulação intensa de pessoas, criando inúmeras possibilidades de obtenção de algum ganho. A apropriação de determinados lugares se faz em função de um conjunto de fatores que vão desde a permissão social para ocupação, menor pressão do poder público e dos munícipes, até as possibilidades de sobrevivência oferecidas pela região.

Neste trabalho, utiliza-se o conceito de território, amplamente utilizado na Geografia assim como na Ciência Política e na Antropologia, a partir de uma perspectiva mais política, que prioriza as relações de poder, do conceito elaborado por Marcelo Lopes de Souza (2013).

Souza afirma que, uma vez que territórios são "antes relações sociais projetadas no espaço que espaços concretos" (2013, p. 96), estes seriam, por definição, "relações de poder espacialmente delimitadas e operando, destarte, sobre um substrato referencial" (2013, p. 96), entendendo poder inerente a toda relação social, de acordo com Michel Foucault.

É preciso destacar, então, que os territórios não são matéria tangível, palpável, mas sim "campos de força", que só existem como projeções espacializadas das relações sociais, enquanto estas durarem. Souza (2013) trata-os, portanto, sob um ponto de vista de um substrato mais referencial que concreto, longe da ideia de "coisificação" do território.

Importa saber, realmente, que

na qualidade de projeção espacial de relações de poder, os recortes territoriais, as fronteiras e os limites podem todos mudar, sem que necessariamente o substrato material que serve de suporte e referência material para as práticas espaciais mudem. (SOUZA, op. cit., p.90)

O autor também considera que, ainda que a definição de território seja o poder e, sobretudo, a dimensão política das relações sociais, a cultura e o simbolismo estão igualmente contemplados no conceito, já que as motivações para conquistar ou defender um território podem ser, por exemplo, de cunho cultural ou econômico. Souza diz: 
O desejo ou a cobiça com relação ao espaço podem ter relação com os recursos naturais da área em questão; podem ter a ver com o que se produz ou quem produz no espaço considerado; (...) e podem se vincular, também, às ligações afetivas e de identidade entre um grupo social e seu espaço. (2013, p.88)

Os malucos de estrada procuram se instalar em espaços públicos com maior movimentação de pessoas na cidade, de modo a oferecer mais recursos para a sobrevivência do grupo, assim como observam o local mais adequado longe dos territórios de outros grupos de rua, assegurando certa distância para que o controle sobre aquela área esteja garantido.

A Pedra de Maluco se constitui como um território conformado a partir das relações de poder estabelecidas com outros grupos da rua, com os comerciantes e os moradores da cidade, além dos órgãos municipais de urbanismo e a polícia, para que seja possível a instalação, a permanência e a perpetuação do espaço de trabalho, de habitat e do grupo propriamente dito naquele espaço público.

No caso da Pedra de Maluco de João Pessoa, utilizar o termo nanoterritório de Souza (2013) também parece apropriado, já que está localizada em um pequeno trecho da Orla de Tambaú, onde existem outras tantas apropriações. O autor traz esse conceito quando trata de uma prática social que ocorre em uma escala geográfica reduzida, no sentido de que as "fronteiras" englobam, por exemplo, uma rua ou um trecho de rua, um prédio ocupado etc.

Na visão do maluco F., a apropriação se dá quando

você tem o seu trabalho, você coloca ali numa calçada, num banco, qualquer lugar, e aquela área, ela, naquele momento, é sua. Então ninguém pode mexer, ninguém pode vender as coisas do outro naquele espaço que você tá ocupando naquele momento.

(Entrevistado F., em 1 de novembro de 2018).

Quando então as Pedras se fixam e se consolidam nos espaços públicos, todos os hábitos de onde expor, onde comer, onde tomar banho, aonde ir ao banheiro também se consolidam, e assim, se outros malucos chegam à cidade, os caminhos já estão trilhados e os hábitos já estão determinados pelos que ali chegaram e fundaram a Pedra.

Entretanto, quando um maluco chega, é necessário certo tempo até que todos que estejam na Pedra se conheçam, desenvolvam uma relação de confiança, que podemos chamar de período de reconhecimento. Tanto dos que chegam quanto dos que já estão na Pedra precisam descobrir se estão convivendo realmente entre malucos, observar se o maluco que chegou tem atitudes que condizem com as regras e a ideologia do grupo para então repassar as dicas e os lugares onde realizar todas as atividades necessárias da vida na rua - relacionadas à vida íntima e à vida profissional.

Parece inevitável que o maluco de estrada sempre vá procurar a Pedra de Maluco, ainda que haja relatos de trechos de viagem que realizem sozinhos. Primeiro 
porque, quando se chega à cidade, a Pedra é o seu ponto de apoio e acolhimento, lá encontra sua família, seus amigos e sua rede de cooperação para uma vida mais confortável na rua. É o lugar onde pode estabelecer relações de confiança, por saber que, naquele espaço, as pessoas compartilham dos mesmos valores. $\mathrm{O}$ grupo se reconhece como família, estabelecendo uma relação de coletividade extremamente íntima pelo processo de identificação.

Segundo, porque a sua atividade de artesanato não funciona bem quando o maluco de estrada está sozinho. Embora eles não estejam presos nem condicionados à existência de uma Pedra para venderem seus trabalhos, já que eles podem oferecer seus produtos onde quer que estejam, a Pedra se configura como um espaço de manutenção de sua forma de vida e de fonte dos valores próprios do movimento: a vida na família de maluco - a malucada. (Figura 02c)
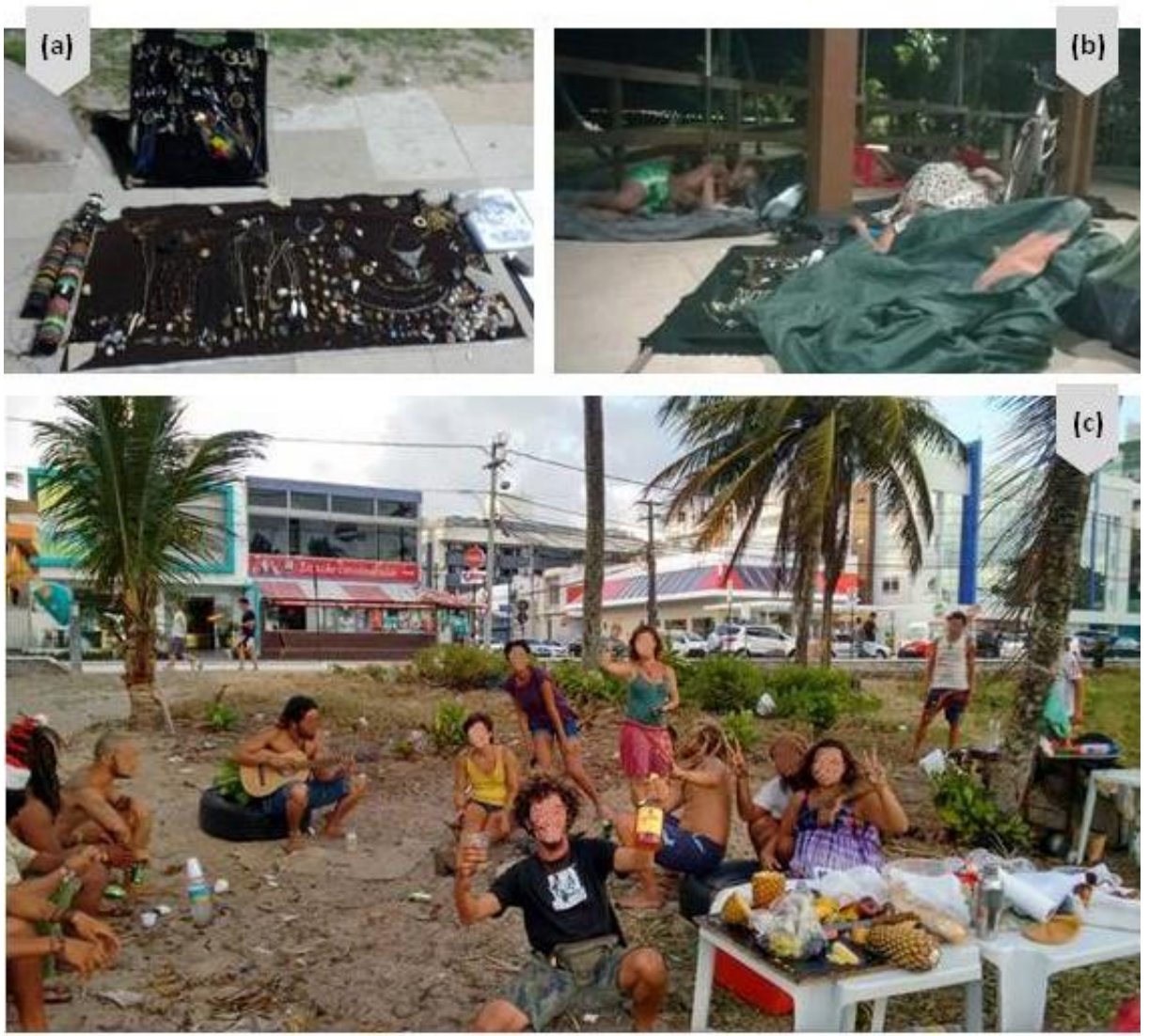

Figura 02 - (a) Pano de chão de um maluco de estrada em João Pessoa/PB. (b) Malucos de estrada dormindo sobre papelões no quiosque Palhoça Baiano com Gaúcho em João Pessoa/PB. (c) A malucada em João Pessoa/PB. Fonte: Fotografias de Mirelli Gomes (2018). 
Nesse sentido, percebe-se que a Pedra de Maluco não está investida somente de condicionantes materiais, mas de valores simbólicos e afetivos, por representar a ideia da família - a malucada, assim como o aprendizado da cultura, do trabalho e da vida em comunidade, em um processo de identificação e pertencimento. Os malucos de estrada criam um vínculo afetivo com aquele espaço, que adquire também a função de construção da sua própria identidade e dos seus valores.

Assim, podemos qualificar que, além de ser um território, ou mais especificamente um nanoterritório, a Pedra de Maluco também pode ser considerada como um Lugar, no sentido da construção de vínculos mais subjetivos na relação dos homens com seu espaço, o que implicaria em processos de identificação e relações de identidade.

Na Geografia anglo-saxônica, lugar quer dizer uma "localização significativa", muito mais do que simples local ou localização, o que compreende uma dimensão subjetiva de um determinado sentimento ou "sentido de lugar", que para Haesbaert (2014) quer dizer a construção de uma identidade do espaço, uma vez que "no lugar estamos 'mergulhados' em todos os sentidos da nossa experiência, do "vivido"” e, portanto, "é um modo de entendimento do mundo“. (HAESBAERT, 2014, p.46)

Entre um deslocamento e outro, o maluco de estrada faz suas pausas, se apropria de um determinado espaço público pelo processo de territorialização, estabelecendo tempos, ritmos e ordens diversas que se adaptam à realidade de cada cidade, bem como as relações sociais necessárias para estabelecer seu habitat, e assim, a partir da experiência e da relação de afetividade com o espaço, reconhece-o como um Lugar.

\section{A Pedra de Maluco de João Pessoa: a apropriação do espaço e a representação do cotidiano}

A apropriação espacial da Pedra de Maluco de João Pessoa acontece na calçadinha da Praia de Tambaú, na Avenida Almirante Tamandaré, em frente a transversal Avenida Nego, ao Bob's Burguers (restaurante fast-food) e à Estação Conveniência (mercearia) e ao lado do quiosque Rango Bar. (Figuras 03a/b)

Nesse trecho da orla, os malucos de estrada armam seus panos de chão na calçada e apoiam seus painéis sobre os bancos de cimento. Mais especificamente, concentram-se no banco mais próximo ao Rango Bar. (Indicado como Banco 1, na Figura 03b) Essa extensão costuma acomodar de 3 a 4 malucos, dependendo do tamanho dos seus panos de chão. 

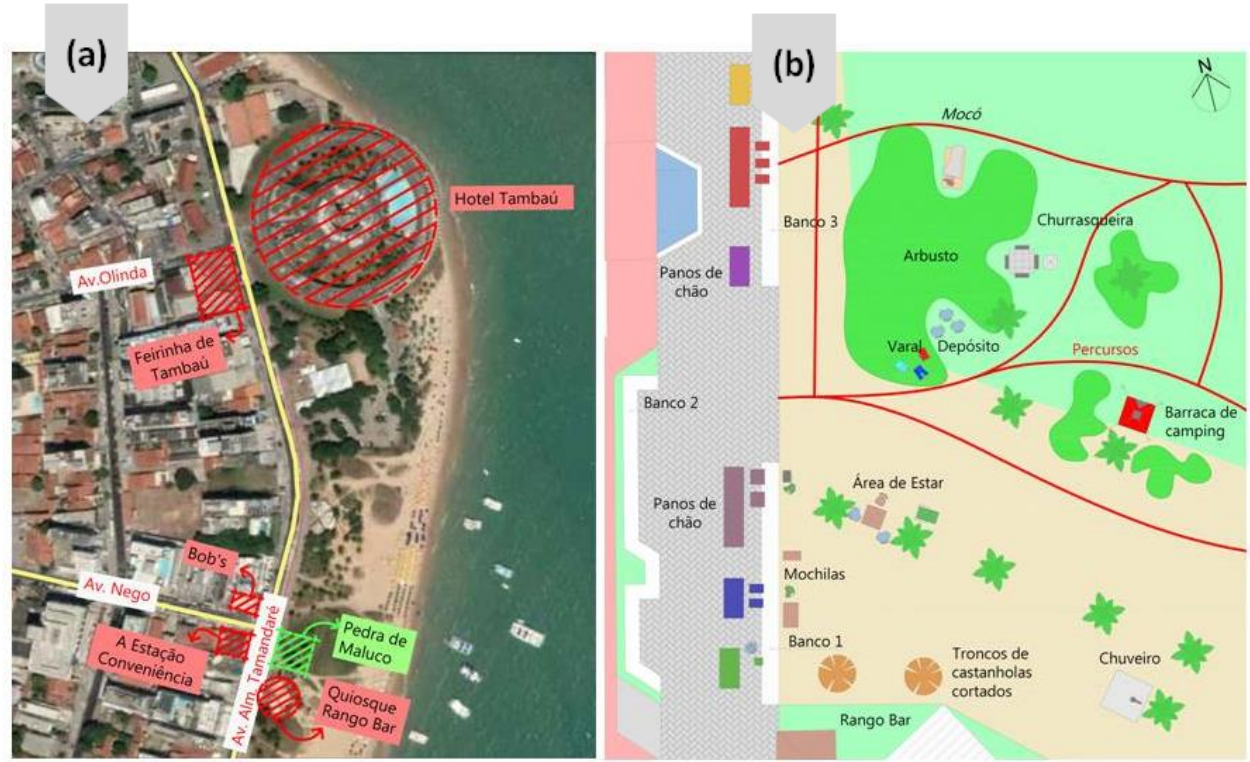

Figura 03 - (a) Localização da Pedra de Maluco em João Pessoa/PB. (b) Representação da Pedra de Maluco de João Pessoa/PB. Fonte: GOOGLE, editado por Mirelli Gomes (2018).

Atrás do banco, eles colocam as mochilas, carrinhos e todos os pertences pessoais, para que o espaço de exposição fique livre de obstáculos. Na areia, organizam um espaço com cadeiras, bancos, papelões e cobertores para sentar e deitar enquanto aguardam os clientes. (Indicado como Área de estar, na Figura 03b). (Figuras 04a/b) Também podem usar os bancos ou o mobiliário urbano para sentar e deitar, como aquele que está imediatamente em frente à Pedra, na mesma calçada. (Indicado como Banco 2, na Figura 03b)

Na Pedra de Maluco de João Pessoa, geralmente há cadeiras de escritório quebradas que foram minimamente rearranjadas pelo grupo, com arames, alicates e linhas que utilizam para o trabalho artesanal. (Figura 04c) Também há mesas quebradas - de plástico ou de madeira, descartadas pelos bares e quiosques ao longo da orla e que são utilizadas para montar uma bancada de trabalho como também para servir de apoio nos momentos de refeições.

De forma geral, os lixos do bairro são muito importantes para a manutenção dessa forma de vida. Assim como as casas, os edifícios e os escritórios fornecem móveis, cadeiras e eletrodomésticos quebrados, os quais os malucos rearranjam e reutilizam, os edifícios em construção fornecem metralhas, pedras e tábuas que servem para construir algum mobiliário ou para montar o pano de chão. Os mercados descartam o material mais utilizado pelos malucos de estrada: caixas de papelão, que eles dispõem sobre o chão ou na areia para sentar ou para dormir. 
Por isso, muitas vezes, realizam percursos pelo bairro a fim de observar lixeiras de casas, prédios ou ir até edifícios em construção a fim de explorar o que está sendo colocado no lixo, o que pode ser coletado e como pode ser aproveitado na Pedra de Maluco.

Em virtude da falta de espaços cobertos ou elementos de coberta no espaço público, todos os móveis vão sendo deslocados ao longo do dia acompanhando o movimento das sombras dos coqueiros. (Figura 04d)
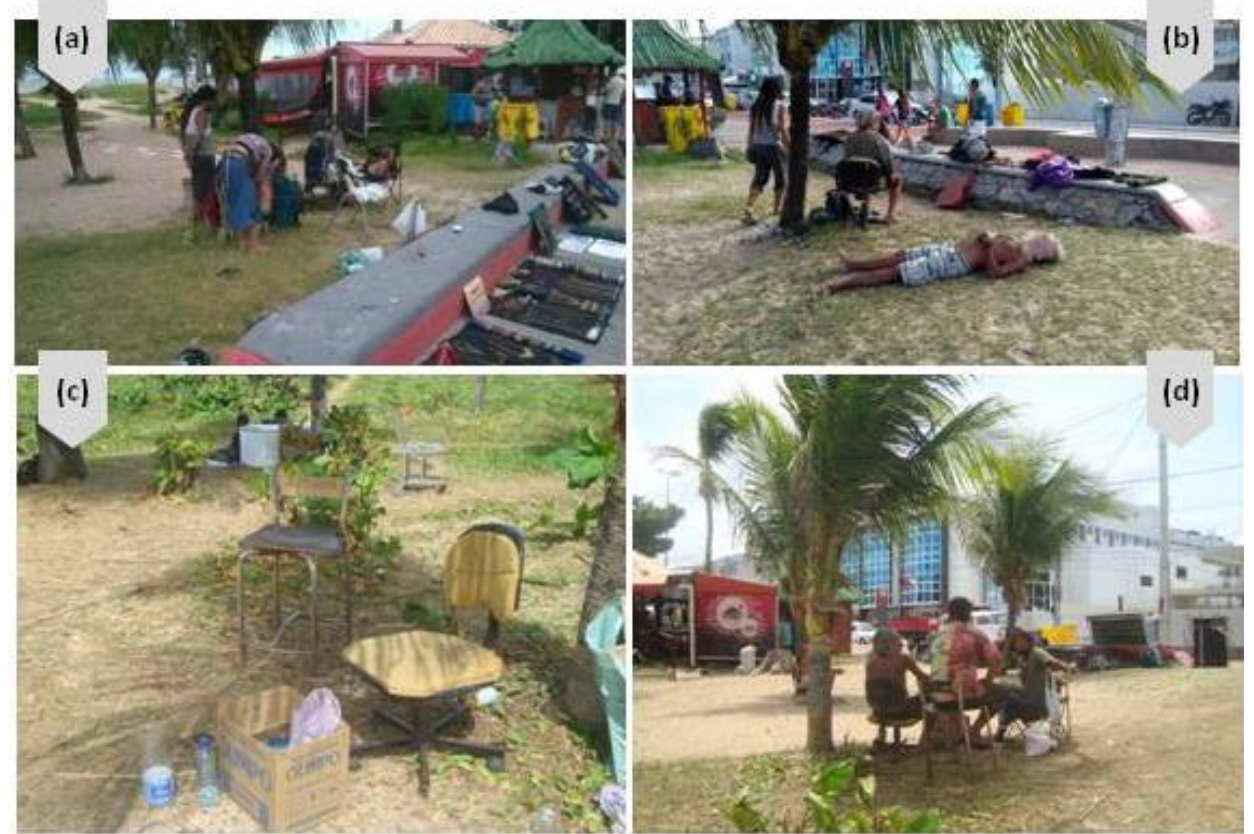

Figura 04 : (a) (b) Área de Estar da Pedra de Maluco de João Pessoa/PB. (c) Mobiliário da Pedra de Maluco de João Pessoa/PB. (d) Malucos de estrada nas sombras dos coqueiros na Pedra de Maluco de João Pessoa/PB. Fonte: Fotografias de Mirelli Gomes (2018).

Se há mais de quatro malucos, o espaço de exposição vai se estendendo até o outro banco que está mais distante, podendo chegar a ser completamente ocupado. (Indicado como Banco 3, na Figura 03b) Atrás desse outro banco, existe a vegetação gramínea de restinga, assim como uma espécie arbustiva que cresce no local é é aproveitada pelo grupo tanto como uma barreira natural, garantindo a privacidade para diversas atividades, quanto como função de depósito para guardar as cadeiras, os móveis, alguns materiais de trabalho, ou qualquer outro objeto que precisa ser escondido durante a noite, enquanto dormem. (Indicado como Arbusto, na Figura 03b) (Figura 05a)

Dentro desta vegetação, também guardam o rastelo e a pá que utilizam para ciscar a areia e limpar o local periodicamente, assim como baldes que utilizam para lavar roupas. 
Depois que lavam, o arbusto também serve de varal, para que coloquem as roupas molhadas para secarem sobre os galhos. (Figura 05b) Se querem dormir durante o dia, colocam-se sob as sombras dos coqueiros, atrás ou dentro do arbusto. (Figura 05c)
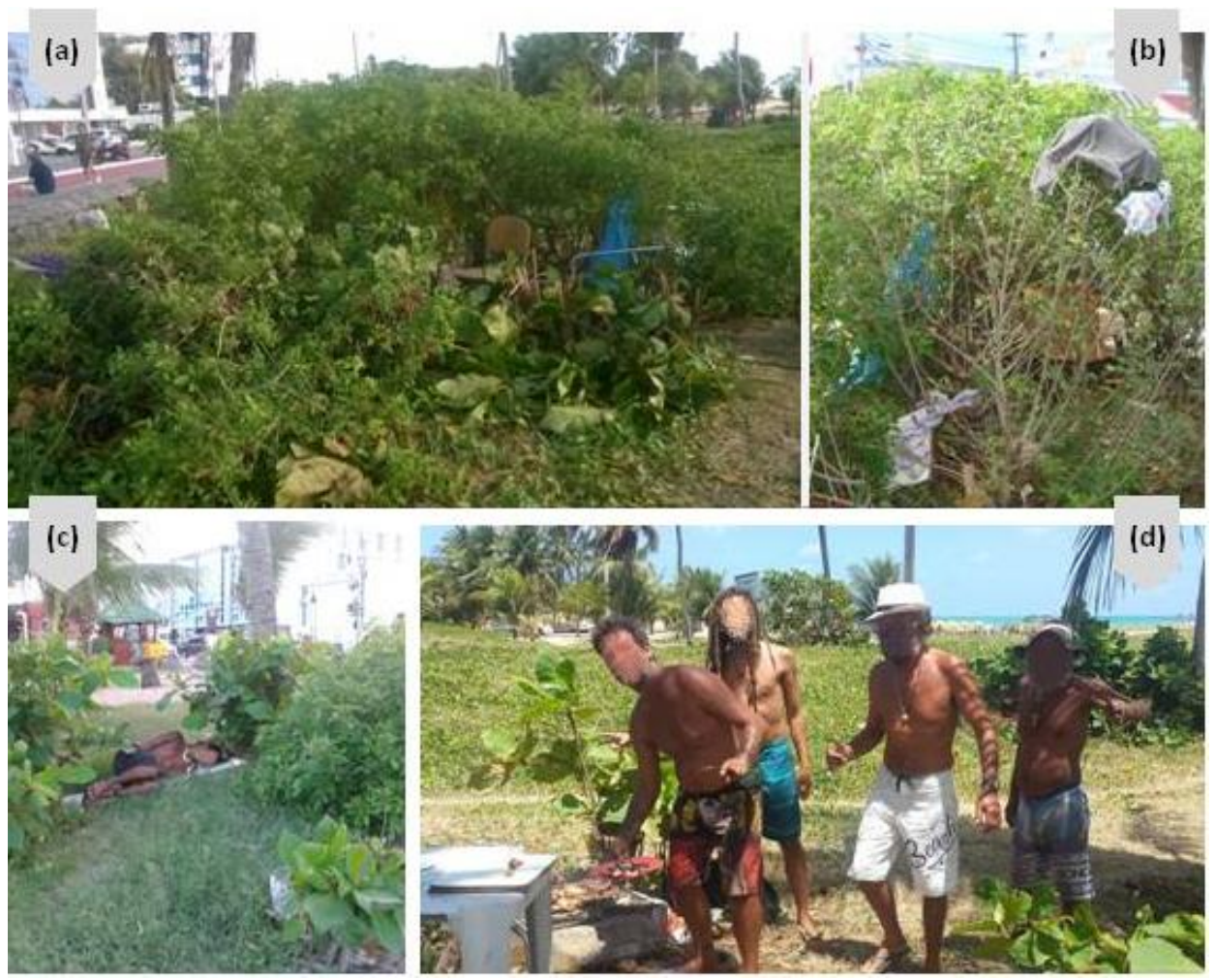

Figura 05 - (a) Arbusto da Pedra de Maluco de João Pessoa/PB. (b) Roupas estendidas sobre o arbusto. (c) Maluco de estrada dormindo atrás do arbusto na Pedra de Maluco de João Pessoa/PB. (d) Churrasco na Pedra de Maluco de João Pessoa/PB. Fonte: Fotografias de Mirelli Gomes (2018).

Atrás da vegetação também organizam a preparação da comida utilizando uma churrasqueira a carvão para cozinhar ou realizar churrasco na hora do almoço. Esse artefato é montado com blocos de concreto chamados de gelo baiano, assim como outras pedras e resíduos de construção civil que catam pela areia da praia, juntamente com grelhas metálicas provenientes de prateleiras de geladeira, armações de ventilador ou qualquer eletrodoméstico. (Indicado como Churrasqueira, na Figura 03b) (Figura 05d)

Sempre que os malucos solicitam, os funcionários do Rango Bar abrem o chuveiro para que possam tomar banho ou lavar as roupas. O chuveiro encontra-se fora do quiosque, mais especificamente na areia, mas o seu sistema de abertura e fechamento está localizado dentro do bar. (Indicado como Chuveiro, na Figura 03b) 
Para dormir à noite, armam barracas de camping na areia, atrás da vegetação, de modo que fiquem camufladas em relação às pessoas que passam na calçada. Se o arbusto está crescido, podem até dormirem sobre papelões, encobertos pela planta. (Indicado como Mocó, na Figura 03b) (Figura 06a)

Na Pedra de Tambaú, é possível estabelecer uma rotina mais ou menos estruturada, já que os acontecimentos dos dias se repetem bastante. Geralmente as atividades começam cedo. Se dormem em barracas de camping, o poliéster, material que compõe as barracas, esquenta facilmente e, então, os malucos são obrigados a deixá-las por volta das $6 \mathrm{~h}$ da manhã, ainda que tenham tido o cuidado de armar sob a sombra dos coqueiros. (Figura 06b)
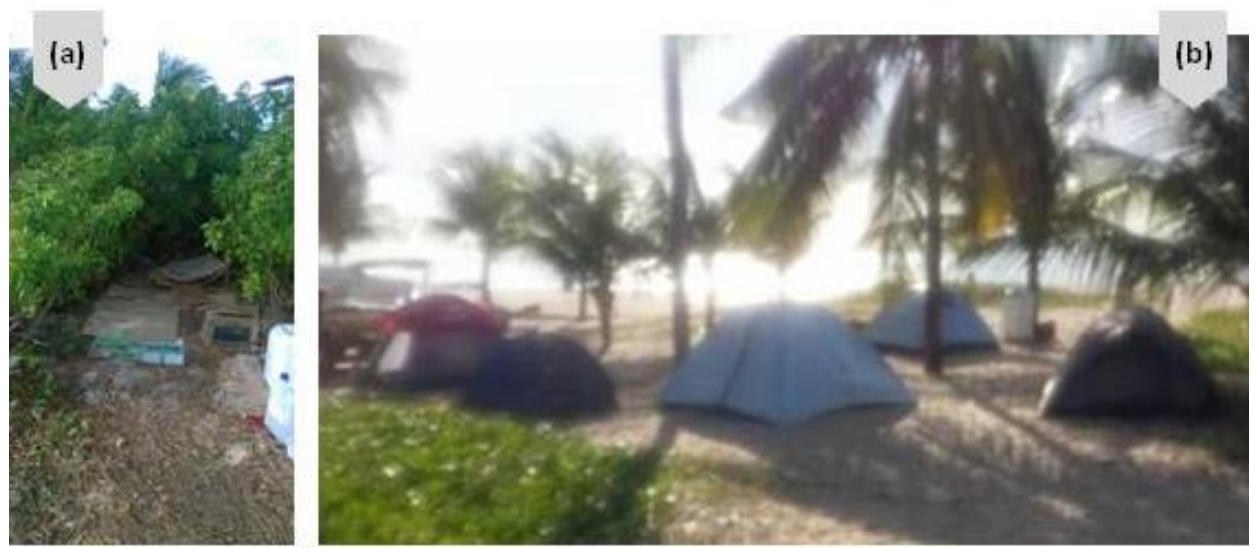

Figura 06: (a) Mocó dentro do arbusto na Pedra de Maluco de João Pessoa/PB. (b) Barracas de camping na Pedra de Maluco de João Pessoa/PB. Fonte: Fotografias de Mirelli Gomes (2018).

Então, após saírem de suas barracas ou do mocó, desarmam as barracas, catam os papelões, juntam suas mochilas e painéis e se dirigem ao Banco 1, onde vão arrumar seus pertences pessoais e o pano de chão com os trabalhos para expor. Então, com todos reunidos na Pedra, começam a se organizar para tomar café da manhã.

Para as situações de alimentação, são observadas diversas maneiras de proceder, mas que estão divididas entre realizá-las individual ou coletivamente. Se fazem isso coletivamente, vão comprar pães e retalhos de queijo no Stok Frios (mercearia), que abre às $7 \mathrm{~h}$ da manhã, para dividir com todos os membros. Alguns malucos vão ao Mercado Público de Tambaú para catar frutas muito maduras ou machucadas que os comerciantes não vão mais vender, ou mesmo comprá-las, para dividir para o grupo.

Quando tomam café da manhã individualmente, vão até a Padaria Flor do Trigo ou ao Restaurante A Nordestina, que servem porções de cuscuz, inhame ou macaxeira acompanhados de frango ou carne bovina guisados. Ou ainda, ficam esperando na Pedra os ambulantes de bicicleta que transitam pela orla ou os que estacionam de carro. Esse tipo de ambulante costuma vir nas primeiras horas da manhã, entre $7 \mathrm{~h}$ e $9 \mathrm{~h}$, para vender salgados, bolos, sucos e café para os funcionários dos quiosques. 
Depois, acomodam-se nas cadeiras, em papelões, em cangas ou até mesmo nos próprios cobertores na areia. (Indicado como Área de estar, na Figura 03b) Nesse espaço, eles ficam reunidos conversando, bebendo, comendo, produzindo novas peças, enfim, praticamente todas as atividades são realizadas ali. Permanecem na Pedra durante todo o dia, já que cada um é responsável em cuidar do seu pano de chão em relação às vendas e às produções de artesanato. Quando precisam sair, vão a estabelecimentos próximos para comprar comidas e/ou bebidas - na Estação Conveniência (mercearia), no Stok Frios (mercearia) ou no quiosque de água de coco, ou ir ao banheiro.

Entre $11 \mathrm{~h}$ e $12 \mathrm{~h}$, quando configura o pico de concentração de pessoas na praia, alguns saem para oferecer os produtos às pessoas que estão na areia bem como naqueles quiosques que permitem a presença deles, indo desde a Pedra de Maluco até a Praia de Cabo Branco, geralmente até o último quiosque que existe na Orla (distante $2,2 \mathrm{~km}$ da Pedra de Maluco) ou até a Praia do Seixas.

No geral, esse movimento pela areia e pelos quiosques costuma acontecer entre $11 \mathrm{~h}$ e $15 \mathrm{~h}$, em média. Depois retornam à Pedra de Maluco, onde vão esperar que o movimento de pessoas recomece no final da tarde, por volta das $18 \mathrm{~h}$, quando muitos habitantes da cidade costumam passear, caminhar ou praticar esportes na calçada.

$\mathrm{Na}$ hora do almoço, quando almoçam individualmente, os malucos fazem revezamento para irem a restaurantes próximos à Pedra de Maluco. Uma parte do grupo vai almoçar, enquanto outra parte fica para atender os clientes e cuidar dos pertences de todos. Os restaurantes mais frequentados são os do tipo self-service que oferecem um prato no valor de $\mathrm{R} \$ 10$, em que se pode servir à vontade com direito a dois pedaços de carne. Os que eles costumam ir são: Pastelaria Ponto Certo (pastelaria e restaurante), Cantinho do Cowboy (restaurante), A Nordestina (restaurante), Restaurante Trânsito (restaurante) ou na Feirinha de Tambaú (praça de alimentação).

Quando decidem comer coletivamente, cozinham alguma comida ou, mais frequentemente, realizam um churrasco. Alguns, então, vão para o Mercado Público de Tambaú, no Empório das Carnes (açougue) ou no Stok Frios (mercearia) para comprar carnes. Depois, vão ao Depósito Ponto 83 Bebidas (depósito de bebidas), A Estação Conveniência (mercearia) ou no Mercadinho Geremias (mercearia) para comprar bebidas como latinhas de cerveja ou garrafas de cachaça e, por fim, também vão comprar carvão na Rua Paulino Pinto, no Bairro de Tambaú.

Realizam o churrasco atrás do arbusto para que a privacidade do grupo seja garantida em relação às pessoas que passam na calçada. Ali montam a churrasqueira e organizam a mesa para manipular os alimentos. Esse churrasco costuma durar do meio dia até às $18 \mathrm{~h}$, em virtude do fim da luz do sol em João Pessoa e do horário de chegada das pessoas à noite.

Quando não fazem churrasco, costumam mudar de local, procurando por sombra. À tarde, o sol incide diretamente na Pedra e, então, vão para o outro lado da Avenida Almirante Tamandaré, onde de fato se faz a sombra da tarde. Eles atravessam, levam parte 
de seus pertences de trabalho para ocuparem a calçada da Estação Conveniência (mercearia) ou da casa vizinha, trabalharem e observarem os clientes que chegam.

Os malucos de estrada permanecem na Orla de Tambaú geralmente até às 0 h. Depois, recolhem todo o mobiliário e guardam dentro do arbusto, em seguida, vão armar suas barracas na areia ou arrumar papelões no quiosque Palhoça Baiano com Gaúcho, com caixas que foram coletadas no lixo do Stok Frios (mercearia), da Estação Conveniência (mercearia) ou de outros lixos do bairro, nos caminhos que tenham percorrido durante o dia.

À noite costumam ir para a Feirinha de Tambaú (praça de alimentação) para jantarem ou esperam ambulantes que passam no período da noite pela orla vendendo milho verde assado e cozido, amendoim, pipoca, hambúrguer ou mungunzá (grãos de milho cozidos no caldo de leite de coco). Há dias em que vão até o restaurante Palace Gourmet ou ao restaurante Terraço Tambaú Trattoria pedir os restos de sopa ou comida que sobrou do buffet da noite.

Os locais frequentados no Bairro em Tambaú - como restaurantes, mercadinhos, bares etc. - foram marcados e indicados na Figura 07. Nesse sentido, os mapeamentos apresentados sugerem a existência de uma circunscrição sócio-geográfica delimitada e a conformação de um nanoterritório (SOUZA, 2013) pelo processo de apropriação (Figura 03b), assim como é possível entender uma determinada área de atuação do grupo a partir dos percursos realizados pelo Bairro de Tambaú, em virtude da possibilidade de sobrevivência oferecida pela região - a oferta de recursos, a presença de comércio e a circulação de pessoas ao longo da orla (Figura 07).

\section{Considerações Finais}

A pesquisa nos possibilitou entender a Pedra de Maluco de João Pessoa como uma espacialização que mais se aproxima de um vazio do que propriamente um espaço edificado ou mesmo ocupado por objetos, já que não há nenhuma construção feita por eles, nem mesmo a ocupação efetiva de algum domicílio. O espaço tem o caráter de fixação temporária e está repleto de códigos, rastros e limites invisíveis.

Ainda que não se configure como uma construção física, o espaço representa a natureza nômade de seus membros e implica em uma modificação dos seus significados e expressões, transformando-o em território como também em um lugar.

O grupo estabelece uma relação de coprodutores do espaço público, nutrindo-se da cidade para transformar a paisagem e o significado do lugar, a partir da criação de um território que expressa a individualidade dos malucos de estrada dentro do universo plural da Orla de Tambaú. 


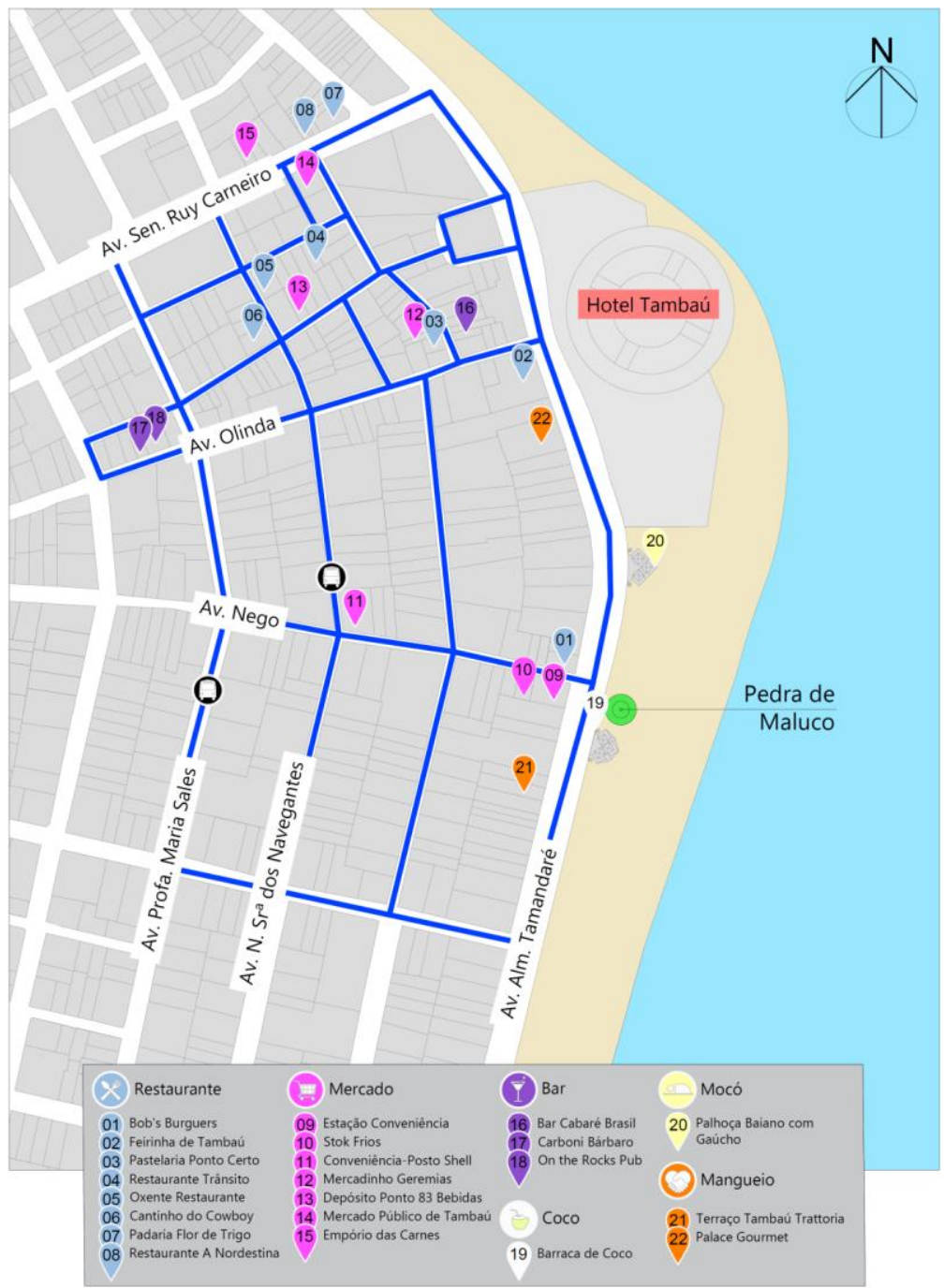

Figura 07: Percursos dos malucos de estrada no bairro de Tambaú, em João Pessoa/PB. Fonte: PMJP, editado por Mirelli Gomes (2018).

\section{Referências Bibliográficas}

BARBOSA, L. L. Design sem fronteiras: a relação entre o nomadismo e a sustentabilidade. Tese de Doutorado (Design e Arquitetura) - Universidade de São Paulo (USP), São Paulo, 2008. 
CARRANZA, E. G. R. Arquitetura Alternativa: 1956-1979. Tese de Doutorado (História e Fundamentos da Arquitetura e Urbanismo) - Universidade de São Paulo (USP), São Paulo, 2012.

DELEUZE, G; GUATTARI, F. Mil platôs: capitalismo e esquizofrenia. v.5. São Paulo: Editora 34, 2012.

GOOGLE. Google Maps. Disponível em: 〈https://www.google.com/maps〉. Acesso em: 02 out. 2018.

GOMES, P. C. da C. Espaços públicos: um modo de ser do espaço, um modo de ser no espaço. In: CASTRO, I. E. de; GOMES, Paulo Cesar da Costa; CORREA, Roberto Lobato. (Org.). Olhares geográficos: modos de ver e viver o espaço. Rio de Janeiro: Editora Bertrand Brasil, 2012. pp. 19-41.

HAESBAERT, R. Viver no limite: território e multi/transterritorialidade em tempos de in-segurança e contenção. Rio de Janeiro: Editora Bertrand Brasil, 2014.

LEFEBVRE, H. A produção do espaço. Tradução de Doralice Barros Pereira e Sérgio Martins, 2006. Disponível em:

<http://www.mom.arq.ufmg.br/mom/arq_interface/1a_aula/A_producao_do_espaco.pdf $>$ (Texto original: La production de l'espace. 4e éd. Paris: Éditions Anthropos, 2000)

MAGNANI, J, G. C. Festa no pedaço: Cultura popular e lazer na cidade. São Paulo: Editora Brasiliense, 1984.

MAIA, D. S. Tempos lentos na cidade: permanências e transformações dos costumes rurais em João Pessoa - PB. Tese de Doutorado (Geografia Humana) - Universidade de São Paulo (USP), São Paulo, 2000.

MALINOWSKI, B. Introdução: o assunto, o método e o objetivo desta investigação. In: DURHAM, E. R. Malinowski. São Paulo: Editora Ática, 1986.

PREFEITURA MUNICIPAL DE JOÃO PESSOA (PMJP). Jampa em Mapas. Disponível em: <http://www.joaopessoa.pb.gov.br/secretarias/seplan/jampa-emmapas/>. Acesso em: 02 out. 2018.

RIBEIRO, A. C. T. et al. Por uma cartografia da ação: pequeno ensaio de método. Cadernos IPPUR, Ano XV, N.2 e Ano XVI, N.1, 2001 e 2002, pp. 33-52.

SOUZA, M. L. de. Os conceitos fundamentais da pesquisa sócio-espacial. Rio de Janeiro: Editora Bertrand Brasil, 2013.

VIEIRA, M. A. da C; BEZERRA; E. M. R; ROSA, C. M. M. (Org.). População de rua: Quem é, como vive, como é vista. São Paulo: Hucitec, 1992.

\section{Nota}

Este artigo é inédito e deriva da dissertação de mestrado de Mirelli Albertha de Oliveira Gomes no Programa de Pós-Graduação em Arquitetura e Urbanismo da Universidade 
Federal da Paraíba, sob a orientação da $\operatorname{Prof}^{a} \operatorname{Dr}^{\mathrm{a}}$ Doralice Sátyro Maia, entitulada "Os malucos de estrada e a apropriação do espaço público em João Pessoa/PB".

\begin{abstract}
Mirelli Albertha de Oliveira Gomes
Mestra pelo Programa de Pós-Graduação em Arquitetura e Urbanismo da Universidade Federal da Paraíba. Graduada em Arquitetura e Urbanismo pela Universidade Federal da Paraíba.

Rua Pastor José Ferreira da Silva, 257, Bessa, 58035160 - João Pessoa, PB. mirelligomes@gmail.com

\section{Doralice Sátyro Maia}

Doutora em Geografia Humana pela Universidade de São Paulo. Possui pósdoutorado pela Universidad de Barcelona e pelo Instituto de Pesquisa e Planejamento Urbano e Regional - IPPUR/UFRJ. Atualmente é Professora Titular da Universidade Federal da Paraíba, do Programa de Pós-Graduação em Geografia e do Programa de Pós-Graduação em Arquitetura e Urbanismo e Colaboradora do Programa de Pós-Graduação em Geografia da Universidade Federal de Pernambuco.

Universidade Federal da Paraíba - Campus I, Centro de Ciências Exatas e da Natureza, Departamento de Geociências, Cidade Universitária, 58059900 João Pessoa, PB.

doralicemaia@hotmail.com
\end{abstract}

